\title{
Violência conjugal: elementos que favorecem o reconhecimento do agravo
}

Marital violence: factors that favor the recognition of appeal

Nadirlene Pereira Gomes', Talita Castro Santos Garcia², Clarissa da Rocha Conceição, Paula de Oliveira Sampaio ${ }^{4}$, Vanessa de Carvalho Almeida5, Gilvânia Patrícia do Nascimento Paixão ${ }^{6}$

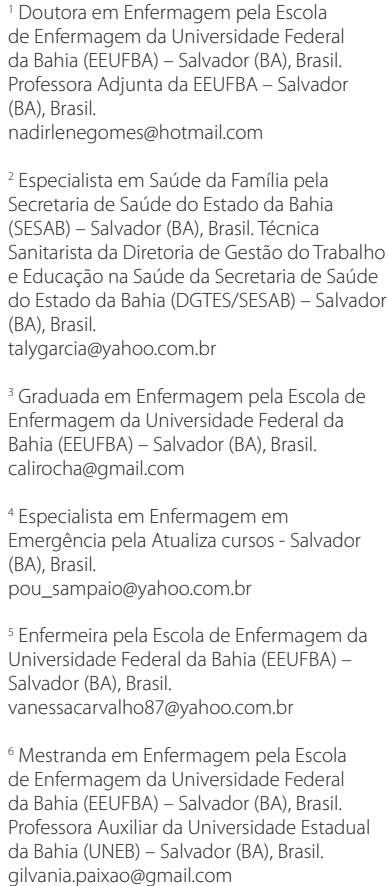

${ }^{3}$ Graduada em Enfermagem pela Escola de Enfermagem da Universidade Federal da Bahia (EEUFBA) - Salvador (BA), Brasil. calirocha@gmail.com

${ }^{4}$ Especialista em Enfermagem em Emergência pela Atualiza cursos - Salvador (BA), Brasil.

pou_sampaio@yahoo.com.br

5 Enfermeira pela Escola de Enfermagem da Universidade Federal da Bahia (EEUFBA) Salvador (BA), Brasil.

vanessacarvalho87@yahoo.com.br

${ }^{6}$ Mestranda em Enfermagem pela Escola de Enfermagem da Universidade Federal da Bahia (EEUFBA) - Salvador (BA), Brasil. Professora Auxiliar da Universidade Estadua da Bahia (UNEB) - Salvador (BA), Brasil. gilvania.paixao@gmail.com

RESUMO Estudo qualitativo, com objetivo de apontar elementos que favoreçam o reconhecimento da violência conjugal como agravo à saúde das mulheres. Realizaram-se entrevista e Análise Temática. O estudo revelou que, além das manifestações visíveis decorrentes da agressão física, a violência conjugal guarda relação com o aborto provocado e com aspectos da saúde mental, tal como a depressão. Os profissionais de saúde suspeitam de violência doméstica diante das sequelas físicas, o que permeia a formação tecnicista de valorização dos aspectos clínicos. Faz-se necessário espaço de discussão sobre a temática da violência doméstica contra a mulher e sobre as questões de gênero durante a formação.

PALAVRAS CHAVE: Violência doméstica; Profissionais da saúde; Qualificação profissional.

ABSTRACT Qualitative study aiming to point out elements that favor the recognition of marital violence as injury to women's health. We conducted interviews and thematic analysis to organize the raw material. The study revealed that besides the visible manifestations resulting from physical assault, domestic violence is related to the abortion and mental health aspects, such as depression. Health workers suspected of domestic violence injuries on physical sequelae, which permeates the technical education to clinical recovery. It is necessary space for discussion on the topic of domestic violence against women and on gender issues during training.

KEYWORDS: Domestic violence; Education health; Vocational education. 


\section{Introdução}

A violência contra a mulher encontra-se ancorada na relação desigual entre masculino e feminino, podendo ser mais bem compreendida tomando-se por base a categoria gênero. Foi com essa perspectiva que a Declaração para a Eliminaçáo da Violência Contra as Mulheres definiu esse fenômeno, como

[...] qualquer ato ou conduta baseada no gênero, que cause morte, dano ou sofrimento físico, sexual ou psicológico à mulher, tanto na esfera pública como na esfera privada. (CONVENÇÃO DE BELÉM DO PARÁ, 1994).

Pesquisas revelam que o número de casos de violência contra a mulher vem crescendo, sobretudo no espaço doméstico, sendo os homens, com quem a mulher mantém ou manteve relação afetiva, os principais agressores (SALVADOR, 2009; PORTUGAL, 2008; PORTUGAL, 2007; SCHRAIBER et al, 2007). Esse tipo de violência doméstica denomina-se violência conjugal. Esta envolve açóes de homens ou mulheres, baseadas no gênero, contra a pessoa com quem se tem um relacionamento íntimo, independentemente de serem legalmente casados ou do sexo dos envolvidos (MIRANDA; PAULA; BORDIN, 2010; BRASIL, 2006).

Com base na naturalização dos papéis socialmente atribuídos a homens e a mulheres ao longo dos anos, Gomes e Diniz (2008) acreditam que, ao se sentir ameaçado e a fim de restabelecer o poder que acredita ter sobre a mulher, o homem se vale de meios para controlar a sua companheira, chegando a usar a força física. Nota-se que a desigualdade de gênero se traduz em relaçóes assimétricas de força e dominação que têm como extremos a manifestação da violência contra as mulheres. Estudo realizado no Brasil revelou que $46 \%$ dos entrevistados acham que esse tipo de violência doméstica ocorre por uma questão cultural: pelo machismo (INSTITUTO AVON, 2011). Esse resultado traz explícito que a supremacia masculina é elemento relevante na ocorrência da violência contra a mulher, em especial, da violência conjugal.

Pesquisa realizada pela Vigilância de Violências e Acidentes, nos anos 2006 e 2007, revelou que $80 \%$ das vítimas de violência são mulheres, das quais, $73 \%$ sofreram agressão física tendo como principal autor homens com quem as mesmas possuem uma relação de afeto e convívio (BRASIL, 2008). O serviço Disque-Denúncia - Disque 180 - registrou 343.063 atendimentos de casos de violência contra a mulher nos sete primeiros meses do ano de 2010 , contra 161.774 no mesmo período de 2009. Em 57\% destes, as mulheres afirmaram que são agredidas física ou psicologicamente todos os dias, e em mais da metade dos casos declararam correr risco de morte (BRASIL, 2010).

No entanto, sabe-se que os números que temos de violência contra a mulher não correspondem à realidade, pois há uma subnotificação dos casos, uma vez que o que ocorre no ambiente doméstico, tido como espaço privado, muitas vezes fica restrito ao mesmo. Além disso, a questão da hierarquia e da relação de poder existente dentro da família dificulta que a própria mulher se reconheça em situação de violência ou mesmo que revele tal circunstância (SILVA et al, 2009; GOMES; DINIZ, 2008).

Vale salientar que a lei no 10.778 , sancionada em 2003, estabelece a notificação compulsória do caso de violência contra a mulher que for atendida nos serviços de saúde, sejam eles públicos ou privados, em todo o território nacional (BRASIL, 2003). A notificação é, portanto, um instrumento importante para dimensionar a magnitude dos casos de violência, todavia, estudos mostram que os profissionais, em geral, não realizam o preenchimento da ficha e referem uma formação profissional que não contemplava a temática (VICENTE; VIEIRA, 2009).

Apesar de ainda não termos um dimensionamento da problemática, estudos deixam clara sua magnitude, apontando o fato de que as mulheres em situação de violência doméstica têm mais problemas de saúde, maiores custos com assistência e utilizam com maior frequência os serviços de saúde, o que gera aumento dos gastos com o setor (ROSA et al, 2008). Nesse contexto, a violência doméstica e conjugal se desvela enquanto 
um problema de saúde pública, uma vez que afeta não só as vítimas, mas também traz implicações para toda a sociedade.

Pesquisa realizada com mulheres atendidas nas clínicas de dor do Rio de Janeiro, que referem dores sem causa palpável, detectou que mais de $90 \%$ das clientes atendidas tinham sofrido ou continuavam sofrendo violência dentro de casa, sendo que $43 \%$ tinham sofrido ou sofriam especificamente a violência sexual (DOMINGUES; MACHADO, 2011).

Estudos revelam que mulheres em situação de violência conjugal apresentam maior chance de realizarem aborto ou de terem crianças com baixo peso ao nascer (LOURENÇO, 2006; DINIZ et al, 2009). Estudo realizado com 906 laudos médico-legais de pessoas com queixa de violência mostrou que as mulheres em situação de violência conjugal são mais vitimizadas, quase sempre apresentando ferimento na boca ou na região mandibular (FARIA, 2006).

A vivência de violência doméstica traz prejuízos nas esferas do desenvolvimento físico e psicológico. Mulheres em situação de violência referem hipertensão arterial, estresse, depressão, ansiedade, compulsão, perda ou aumento excessivo de peso, aborto, entre outros danos físicos e psicológicos. Nesse contexto, a vivência de violência desencadeia vários problemas de saúde e representa uma ameaça à vida (GUEDES; SILVA; FONSECA, 2009; DINIZ et al, 2009). Assim, independentemente do espaço de saúde, os serviços de saúde são locais estratégicos para a identificação de mulheres em vivência de violência.

Gomes (2009), entretanto, sinaliza para o despreparo do profissional, que muitas vezes não sabe ou não direciona sua escuta e seu olhar para diagnosticar uma situação de violência. A autora refere que os profissionais, inclusive das unidades de emergência, pouco relacionam os problemas que levam as mulheres aos serviços de saúde com a situação de violência. Necessário se faz um cuidado em saúde que garanta o atendimento integral à mulher em situação de violência doméstica, o que requer investigação do agravo, cuidado prestado técnica e legalmente e encaminhamentos para outros serviços da rede de atenção à mulher em situação de violência.
Considerando as repercussóes da violência conjugal para o setor da saúde e a importância dos profissionais na identificação desse agravo, no sentido de prevenir e enfrentar a problemática, o presente estudo tem como objetivo apontar elementos que favoreçam o reconhecimento da violência conjugal como agravo à saúde das mulheres.

\section{Métodos}

O estudo foi realizado em serviços que integram a Rede de Atenção a Pessoas em Situação de Violência na cidade de Salvador, Bahia, Brasil. Colaboraram com o estudo, sete serviços: Centro de Orientação Familiar (COF), Centro de Referência Loreta Valadares (CRLV), 2 hospitais de urgência e emergência, 01 maternidade e 02 unidades de saúde de pronto atendimento. O COF é uma entidade civil com fins não econômicos, existente em todo o Brasil, com missão de prestar serviço social, psicológico e terapêutico para ajudar famílias em situação de vulnerabilidade, sobretudo no sentido de favorecer as relaçóes interpessoais entre os casais. O CRLV é um centro de referência na Bahia, que oferece atendimento jurídico, psicológico e social para mulheres em situação de violência e atenção pedagógica aos filhos das usuárias. No caso das instituiçóes de saúde, as mesmas integram serviços de pronto atendimento e ambulatorial que compóem a esfera pública, privada e filantrópica. A escolha desses estabelecimentos se justifica por se tratar de locais que contemplam tanto o nível ambulatorial como emergência e urgência, e que, portanto, encontram-se em posição estratégica para identificação dos casos de violência.

A aproximação com esses serviços foi viabilizada pelo apoio do Fórum de Combate à Violência, que auxiliou no processo de identificação e contato com as instituições. Os serviços foram contatados quando foram esclarecidos os objetivos e a relevância do estudo, e solicitada a permissão para a coleta de dados. Os sujeitos, escolhidos de forma aleatória, foram convidados a colaborar com o estudo. Participaram dele 12 profissionais, sendo 02 psicólogos, 06 
enfermeiros, 02 assistentes sociais, 01 fisioterapeuta e 01 médico.

Como técnica de coleta de dados, optou-se pela entrevista, realizada após aprovação do projeto pelo Comitê de Ética em Pesquisa do Hospital Santo Antônio, sob no 31/07. Aos sujeitos também foram esclarecidos os objetivos e a relevância do estudo, além de aspectos éticos, conforme preconiza a Resolução 196/96 (BRASIL, 1996), e solicitada assinatura do Termo de Consentimento Livre e Esclarecido.

Elegeu-se como técnica de análise dos dados a Análise Temática. Essa técnica permite encontrar, pela sua presença no discurso, o núcleo de significação que se mostra no texto, ou seja, o tema. A operacionalização da análise temática se desdobra em três etapas, descritas por Bardin (2009): pré-análise; exploração do material; tratamento dos resultados, inferência e interpretação. Após a leitura flutuante e o contato exaustivo com o conteúdo das respostas, foram encontradas categorias que nortearam o processo de sistematização, interpretação e análise de dados. São elas: Problemas de saúde e a vivência de violência doméstica pela mulher; Formação profissional que contemple a violência doméstica.

\section{Resultados}

O estudo mostrou que os profissionais reconhecem que a violência doméstica, sobretudo a conjugal, repercute na saúde da mulher. Como elementos que favorecem tal reconhecimento, o estudo sinaliza para a necessidade de associação dos problemas de saúde com a violência doméstica e, portanto, de investigação do fenômeno. Aponta-se, ainda, para a necessidade de mudanças nos currículos de formação em saúde.

Os profissionais dos serviços de saúde entrevistados vinculam a violência doméstica às lesóes físicas, enquanto os demais, possivelmente por atuarem em espaços que trabalham especificamente a questão da violência doméstica, apresentam um olhar mais abrangente acerca do fenômeno, contemplando as implicaçóes para a saúde mental e reprodutiva das mulheres.

\section{Associando problemas de saúde à vivência de violência doméstica pela mulher}

Muitos são os problemas de saúde que podem guardar relação com a violência doméstica. Necessário se faz que os profissionais investiguem tal associação. $\mathrm{O}$ estudo mostrou que o reconhecimento da vivência de violência pela mulher pode se dar por meio de sinais e sintomas relacionados a lesóes físicas, problemas psicológicos ou por comprometimento da saúde reprodutiva.

\section{Olhar para as marcas físicas}

As falas dos profissionais que atuam nos espaços da saúde sugerem que o agravo é reconhecido quando associado às marcas visíveis que as mulheres apresentam, sendo sugestivas de violência:

Domingo agora teve um caso. Eram nitidos dois hematomas e edema. A gente logo pensou em alergia, mas desconfiamos de agressão devido ao hematoma palpebral [...].(E3 Enf. Centro de Saúde).

[...] traumas em face, hematomas pelo corpo, especialmente, em membros, dores abdominais [...]. Desconfiei porque os tipos de lesóes não condiziam com o acidente que a pessoa relata ter sofrido. (E10 Enf. Hospital).

Nota-se, ainda, que as experiências profissionais lhes dão respaldo para essa identificação e os colocam em posição estratégica para a suspeita e a investigação do episódio de violência sofrido, ainda que as informações sobre a situação não sejam descritas claramente.

[...] tem a lesão [...] mas também falta coerência do problema de saúde com a história apresentada. (E1 Enf. Centro de Saúde). 
$\mathrm{Na}$ verdade, náo foi ela quem falou que o machucado na barriga foi o namorado. A gente percebeu pela situação. Depois, ela confirmou. (E11 Enf. Maternidade).

As falas trazidas pela categoria de enfermagem deixam clara a violência doméstica como pano de fundo para a busca do serviço e nos permitem compreender a importância dos profissionais no processo de identificação da violência conjugal.

Vale destacar que os profissionais das categorias de enfermagem e médica referiram direcionar os casos de violência identificados para o serviço social. No entanto, sabe-se que, por não estar diretamente em contato com os usuários, a assistente social recebe apenas os casos de violência encaminhados, o que reforça a importância de um olhar para além dos aspectos físicos por parte das categorias de enfermagem e médica.

\section{Olhar para a saúde reprodutiva}

Embora os profissionais que atuam nos serviços de saúde não tenham sinalizado para a associação da violência doméstica com a saúde reprodutiva, os profissionais do CRLV demonstraram uma compreensão de que a violência encontra-se associada ao aborto provocado, conforme ilustra o seguinte depoimento:

O aborto também está bastante associado ao evento da violência: 'Eu abortei porque não quero ter aquele filho, naquela hora, com aquele homem. (E6 Psic. CRLV).

Percebe-se, pois, que a violência interfere no processo de saúde reprodutiva das mulheres, de modo que o setor saúde representa lócus privilegiado para identificação dessas situações. A investigação de tal agravo é essencial para a definição do plano de cuidado direcionado à mulher, e requer do profissional atendimento técnico e também encaminhamento, considerando as demandas apresentadas.

\section{Olhar para a saúde mental}

Problemas relacionados à saúde mental foram apontados pelos entrevistados como sinais e sintomas sugestivos da vivência de violência doméstica pela mulher, sinalizando para um comprometimento da saúde mental da mesma:

\section{Alguns problemas têm relaçâo direta com a vio- lência [...]. A mulher que tem depressão e ideia suicida [...]. Alguns atendimentos são bastan- te dificeis. Chocantes! De me deixar, às vezes, muito abalada mesmo! De pensar "Como uma situação dessa é possivel? (E6 Psic. CRLV).}

Chama atenção que, com base nas falas dos profissionais de saúde entrevistados (enfermeiras e médico), esses sinais e sintomas de ordem psicológica não venham sendo associados à vivência de violência.

Vale referir que não só as profissionais do CRLV, mas a profissional do COF também reconhece a violência para além dos traumas físicos, demonstrando uma compreensão mais ampla da violência, o que possivelmente está associado ao olhar diferenciado para essas questóes. Vejamos os depoimentos:

\section{[...] Quando elas chegam ao nosso atendimen-} to, não nos trazem diretamente a questão da violência. Elas vêm por conta de outras questóes[...]. Muitos casos de depressão [...]. Ela ia falando das queixas dela, da tristeza dela [...]. Quando a gente vai fazer a investigação, a gente vê em qual contexto que estas mulheres estão vivendo, e ai a gente descobre que tem casos de violência. Eu entendo a realidade dela: ela não trabalha, ela vive na casa que pertence ao esposo. É como se pensasse 'Não tem mais jeito, eu já sofro essa violência', como se fosse naturalizando mesmo. (E12 Psic. COF).

É um sofrimento diário, mas com muito desconhecimento também por parte dela [...]. Quando elas chegam no serviço é uma descoberta a cada atendimento [...]do que não é natural [...] do que não é normal [...] do que eu não posso passar [...] do que eu não preciso passar. Mas, no seu discurso, você percebe que ela naturaliza aquilo. (E7 Ass. Soc. CRLV). 
Eu acho que quem está de fora, às vezes, não conhece o drama dessas mulheres. Para quem conhece, normalmente, percebe. (E6 Psic. CRLV).

As falas das profissionais desses serviços sinalizam para uma percepção da violência doméstica enquanto um fenômeno complexo, o que viabiliza o reconhecimento de mulheres inseridas nesse contexto, independentemente do cenário: sala de aula, interação em comunidades, relações com amigos e família, espaço da atenção básica ou unidades de emergências, visitas domiciliares etc.

Chama atençáo que essa compreensão não se deu durante a formação, sendo buscada por conta da atuação em serviço específico de atenção a mulheres em situação de violência. Os discursos sinalizam para um atendimento diferenciado, com um olhar atento e uma escuta ativa, confirmando a relevância de tal espaço para o fortalecimento das mulheres no sentido de anular a violência que permeia a relação conjugal.

\section{Formação profissional que contemple a violência doméstica}

O olhar que possibilita o reconhecimento da vivência de violência doméstica pela mulher ancora-se na compreensão acerca da complexidade do fenômeno. As falas apontam para a necessidade de que se instiguem as discussóes sobre questóes de gênero no processo de formação dos profissionais de serviços que recebem ou possam vir a receber mulheres que vivenciam a violência conjugal, não se restringindo àqueles específicos da atenção a pessoas em situação de violência. Os depoimentos a seguir permitem ilustrar tal situação:

Na faculdade, vê muito pouco sobre o tema. (E11 Enf. Maternidade).

Eu acho que na graduação poderia ter uma disciplina do currículo minimo que abordasse as questóes das politicas públicas, e que, a partir destas, fosse inserido a questão da mulher. (E6 Psic. CRLV).
O profissional médico, ele não é formado para isso [...] não tem essa formação. A gente tem uma matéria, psicologia médica, mas eu acho que não é um semestre ou dois dessa matéria que vai fazer com que você seja sensibilizado para essas questôes. (E8 Méd. Hospital).

A gente percebe hoje como foi dificil se aproximar da temática por conta da questão do trabalho [...]. Muitas coisas do nosso próprio discurso tiveram que ser desconstruido [...] um discurso machista e aquilo foi sendo quebrado [...] quantas dificuldades para se aproximar disso com um outro olhar[...]. Não ter esse olhar é um dificultador muito grande. Eu acho que tinha que ter uma cadeira voltada realmente para estar estudando as questóes de gênero [...] estar estudando todas as questóes relacionadas à violência. (E7 Ass. Soc. CRLV).

Sob essa perspectiva, é imperativa uma transformação do modelo de formação dos profissionais, direcionando seus currículos para a interface social e possibilitando espaços que discutam a violência, sobretudo a violência doméstica contra a mulher, uma vez que as universidades possuem papel importantíssimo na produção de conhecimentos relevantes, na formação de profissionais adequados às necessidades sociais, na prestação de serviços oportunos e de qualidade, compartilhando de uma política de saúde voltada para as necessidades da maioria da população.

\section{Discussão}

O estudo deixa claro que, além de danos físicos, a violência compromete a saúde reprodutiva e mental das mulheres. No entanto, diante de um evento traumático com sequelas físicas, os profissionais de saúde entrevistados suspeitam de violência doméstica, mas não mencionam outros sinais além das lesôes visíveis, visão essa que permeia a formação tecnicista de valorização dos aspectos clínicos. 
$\mathrm{Na}$ área da saúde, foi marcante a excessiva especialização técnica, com enfoque funcionalista, e a assistência curativa fundamentada na observação de sinais e sintomas de quadros clínicos (ARCOS et al, 2007). Dessa forma, os profissionais de saúde não questionam a mulher vítima de violência a respeito da origem dos ferimentos, voltando-se apenas para a assistência curativa medicamentosa.

A limitação às evidências físicas por parte dos profissionais de saúde direciona para uma assistência fragmentada, visto que o grupo de mulheres com lesão física revela uma pequena parcela de um problema muito mais complexo (GOMES, 2009). Nesse contexto, Vieira, Perdona e Santos (2011) referem que os profissionais devem estar preparados e, principalmente, atentos para identificar o fenômeno, que nem sempre deixa marcas visíveis.

Com relação à saúde reprodutiva, estudos têm evidenciado que a violência contra a mulher encontra-se associada a dores pélvicas crônicas, DST/AIDS e doenças pélvicas inflamatórias, gravidez indesejada e aborto (BAPTISTE, 2007). Corroborando, Diniz et al (2009) acreditam que a vivência de violência conjugal guarda relação com o aborto provocado. Em seu estudo, das 147 mulheres com esse histórico, 27,9\% declararam ter sofrido violência conjugal, sendo que $67 \%$ afirmaram que a decisão de abortar decorreu por conta da violência sofrida.

No que tange ao sofrimento psíquico, os sintomas psicológicos frequentemente encontrados incluem insônia, pesadelos, falta de concentração, irritabilidade, falta de apetite e até o aparecimento de problemas mentais sérios, como a depressão. Pesquisas revelam que a vivência de violência doméstica é um importante fator de risco para a depressão, inclusive em mulheres que sofrem agressões durante a gestação (AUDI et al, 2008).

Vale salientar que a violência doméstica, além de trazer repercussóes amplas para as vítimas, sobretudo sob o aspecto psicológico, também compromete a saúde mental dos profissionais, especialmente daqueles que lidam diariamente com as histórias de violência e compartilham da dor das mulheres. Os profissionais necessitam lidar com sua própria angústia diante das limitaçóes humanas, experimentando sentimentos de impotência, tristeza e angústia (CORREA; LABRONICI; TRIGUEIRO, 2009).

Percebe-se, assim, a importância de um melhor preparo profissional para a identificação da violência doméstica como causa primária ou pano de fundo para a busca pelo serviço, como também para lidar com a problemática. $\mathrm{O}$ estudo revelou que a formação acadêmico-profissional não contempla a temática violência doméstica, tampouco aspectos relacionados à construção social da desigualdade de gênero, o que guarda relaçấo com a dificuldade de reconhecimento do agravo.

Assim sendo, é fundamental que as universidades possibilitem aos discentes espaços que favoreçam a compreensão acerca da complexidade da violência contra a mulher e açóes no sentido de desconstruir as concepçóes machistas ancoradas na desigualdade de gênero, responsáveis pela não identificação da violência doméstica como elemento que faz adoecer as mulheres e pelos julgamentos que se mostram na relação interpessoal durante a assistência. Situação que leva à revitimização pela violência institucional (GOMES, 2009). A Lei 11340, inclusive, já preconiza a inclusão de conteúdos relativos à equidade de gênero e ao problema da violência doméstica e familiar contra a mulher em todos os níveis de ensino (BRASIL, 2006).

Considerando que os profissionais de saúde, por muitas vezes, representam a única chance de ajuda para mulheres em situação de violência, torna-se essencial o desenvolvimento da escuta qualificada e do olhar treinado para identificar e notificar os possíveis casos de violência doméstica (SALIBA et al, 2007). É um trabalho que requer do profissional um olhar diferenciado, atento aos sinais e sintomas apresentados, sejam eles físicos ou psicológicos, que sinalizem, por exemplo, para episódios de violência conjugal. Daí, a importância de uma assistência sob a perspectiva da integralidade, a qual visa compreender o indivíduo nos seus aspectos físicos, psicológicos e sociais.

Pesquisa realizada com profissionais que atendem mulheres vítimas de violência sexual mostrou que o acolhimento é um fator essencial para uma assistência humanizada e individualizada, assim como é fundamental para estabelecer vínculo e proporcionar um ambiente favorável às usuárias (REIS et al, 2010). Nesse 
contexto, humanizar implica solidariedade para com a dor do outro, a fim de alcançar um modelo de cuidado que vá além da objetividade do tratamento de lesôes e que seja capaz de estabelecer uma relação de respeito e confiança que permita o processo de acolhimento e fortalecimento.

\section{Considerações Finais}

O estudo revelou que, além das manifestações visíveis, decorrentes da agressão física, a violência conjugal guarda relação com o aborto provocado e com aspectos da saúde mental, tal como a depressão. Por esses e outros problemas de saúde desencadeados na mulher, os serviços de saúde constituem-se porta de entrada para os casos de violência doméstica, sendo essencial a investigação de tal associação a fim de garantir um atendimento que perpasse os aspectos clínicos, considerando as especificidades desse tipo de violência.

O estudo também sinaliza para a necessidade de uma formação profissional que favoreça a identificação da violência doméstica. Acredita-se que a compreensão da complexidade da violência doméstica contra a mulher possibilitará a identificaçáo de um maior número de mulheres em situação de violência e a adoção de condutas mais adequadas às suas demandas, o que, por sua vez, requer articulação intersetorial com serviços de outras áreas, como os centros de referência às mulheres em situação de violência doméstica.

Este estudo poderá contribuir para a melhoria da qualidade da atenção a mulheres em situação de violência, uma vez que traz elementos relacionados à dificuldade de identificação de tais casos nos espaços da saúde e à necessidade de se repensar o processo de formação.

\section{Referências}

ARCOS G. E. et al. Perspectiva de género en la formación de profesionales de la salud: Una tarea pendiente. Revista Médica do Chile, Chile, v.135, p. 708-717, 2007.

AUDI, C. A. F. et al. Violência doméstica na gravidez: prevalência e fatores associados. Revista de Saúde Publica, São Paulo, v. 42, n. 05, p.877-885, 2008.

BAPTISTE, M. HC. Violência doméstica: consequências para a mulher. 2007. 196f. Dissertação (Mestrado de Saúde Pública) - Faculdade de Saúde Pública, Universidade São Paulo, São Paulo, 2007.

BARDIN, L. Análise de conteúdo. Lisboa: Edições 70, 2009. 223p.

BRASIL. Conselho Nacional de Saúde. Resolução no 196. Dispõe sobre pesquisa envolvendo seres humanos. Revista Bioética, Brasília, v.4, n.1, p.15-25, 1996

Lei n. 10.778, de 24 de novembro de 2003. Notificação compulsória da violência contra a mulher. Brasília: Presidência da República, 2003. Disponível em <http://www6.senado.gov.br/ legislacao/ListaTextolntegral. action?id=225310\&norma=237891 >. Acesso em: 15 abr. 2007.

Lei n. 11.340, de 7 de agosto de 2006. Brasília: Presidência da República, 2006. Disponível em: < http://www.planalto.gov.br/ ccivil/_Ato2004-2006/2006/Lei /L11340.htm>. Acesso em: 15 abr. 2007.
- Ministério da Saúde. Secretaria de Vigilância em Saúde. Área Técnica de Vigilância e Prevenção de Violências e Acidentes. Caracterização das vítimas de violências doméstica, sexual e outras violências interpessoais notificados no VIVA. Norma técnica. 2. ed. atual. e ampl. Brasília; 2008.

Secretaria de Políticas para as Mulheres da Presidência da República. Central de Atendimento à Mulher. Norma técnica. 5. ed. Brasília; 2010.

CONVENÇÃO DE BELÉM DO PARÁ. Convenção Interamericana para Prevenir, Punir e Erradicar a Violência contra a Mulher. Belém: Convenção de Belém do Pará, 1995. 8p.

CORREA, M. E. C; LABRONICI, L. M; TRIGUEIRO, T.H. Sentir-se impotente: um sentimento expresso por cuidadores de vítimas de violência sexual. Revista Latino Americana de Enfermagem, São Paulo, v. 17, n.03, p.289-294, 2009

DOMINGUES, B.; MACHADO, K. Às vítimas de violência sexual, atendimento humanizado. Radis: comunicação em saúde, Rio de Janeiro, n. 92, p. 10-15, abr. 2011.

GOMES, N. P. Trilhando caminhos para o enfrentamento da violência conjugal. 2009. 220f. Tese (Doutorado em Enfermagem) - Escola de Enfermagem, Universidade Federal da Bahia, Salvador, 2009. 
GOMES, N. P.; DINIZ, N. M. F. Homens desvelando as formas de violência conjugal. Acta Paulista de Enfermagem, São Paulo, v. 21, n.2, p. 262-267, 2008.

GUEDES, R. N; SILVA, A. T.M. C; FONSECA, R. M. G.S. A Violência de Gênero e o Processo Saúde-Doença das Mulheres. Revista Anna Nery de Enfermagem, Rio de Janeiro, v.13, n.03, p.625-631, 2009.

INSTITUTO AVON. Pesquisa Instituto AVON/IPSON: percepções sobre a violência contra a mulher no Brasil. São Paulo: IPSON, 2011. 17p.

MIRANDA, M.P.M; PAULA, C. S.; BORDIN, I. A. Violência conjugal física contra a mulher na vida: prevalência e impacto imediato na saúde, trabalho e família. Revista Panamericana de Salud Publica, Washington, DC, v. 27, n.4, 2010.

PORTUGAL. Plano Nacional Contra a Violência Doméstica. Lisboa: Presidência da República, 2007. Disponível em: < http://www. portugal.gov.pt/NR/rdonlyres/DA3EF4A0-74A1-4531-BC086A8714E295AB/0/III_PNCVD.pdf. >. Acesso em: 25 nov. 2008.

Violência doméstica: números em Portugal são intoleráveis. Lisboa: Presidência da República, 2008. Disponível em: < http://www.mp.gov.pt/mp/pt/ Gablmprensa/NoticasLusa/ GC15/20031125_Violencia_Domestica.htm>. Acesso em: 05 nov. 2008.

REIS, M. J. et al. Vivências de enfermeiros na assistência à mulher vítima de violência sexual. Revista de Saúde Pública, São Paulo, v.44, n.02, p.325-331, 2010.
ROSA, A. G. et al. A violência conjugal contra a mulher a partir da ótica do homem autor da violência. Revista Saúde e Sociedade, São Paulo, v.17, n.3 p.152-160, 2008.

SALIBA, O. et al. Responsabilidade do profissional de saúde sobre a notificação dos casos de violência doméstica. Revista de Saúde Pública, São Paulo, v.41, n.03, p. 472-477, 2007.

SALVADOR. Superintendência de Políticas para Mulheres. SPM promovendo políticas para todas as mulheres: dados estatísticos. Salvador: Superintendência de Políticas para Mulheres, 2009. Disponível em: <http://www.spm.salvador.ba.gov.br/index. php?option=com_content\&task $>$. Acesso em: 13 abr. 2009.

SCHRAIBER, L. B. et al. Prevalência da violência contra a mulher por parceiro íntimo em regiões do Brasil. Revista de Saúde Pública, São Paulo, v. 41, n. 5, p.797-807, out. 2007.

SILVA, P. A. et al. Notificação da violência intrafamiliar contra criança e adolescentes na percepção dos profissionais de saúde. Ciência, Cuidado e Saúde, Maringá, v.06, n. 02, p.56-62, 2009.

VICENTE, L. M.; VIEIRA, E. M. O conhecimento sobre a violência de gênero entre estudantes de medicina e médicos residentes. Revista Brasileira de Educação Medica, Rio de Janeiro, v. 33, n.1, p. 63-71, 2009.

VIEIRA, E. M.; PERDONA, G. S. C.; SANTOS, M. A. Fatores associados a violência física por parceiro íntimo em usuárias de serviço de saúde. Revista de Saúde Pública, São Paulo , v. 45, n. 4 . 2011. Disponível em: <http://www.scielo.br/scielo.php?script=sci_ arttext\&pid =S0034-89102011000400013\&tlng=pt. . . Acesso em: 01 set. 2011.

Recebido para publicação em Maio/2012 Versão definitiva em Setembro/2012

Suporte financeiro: não houve

Conflito de interesse: inexistente 